\title{
Tonsillar melanoma
} metastasis

\begin{abstract}
Lidiane Maria de Brito Macedo Ferreira ${ }^{1}$, Érika Ferreira Gomes $^{2}$, Maria do Socorro Barros da Silva ${ }^{3}$, Roberta de Paula Araújó, Adson Sales do Nascimento Rios ${ }^{5}$
\end{abstract}

\section{INTRODUCTION}

Malignant melanoma is an aggressive cutaneous melanocytic neoplasia of fast spread1.

Despite its diagnosis, the disease mortality still reaches high levels. Metastasis to the oral cavity of the cutaneous melanoma is rare2-5: until 2001 less than 30 cases of metastasis in the palatine tonsils had been published3. This type of dissemination is blood-born and the prognosis is deleterious. The reasons for presenting this case are the fact of being a rare finding and the importance of early diagnosis, since the oral cavity is not always examined as routine by clinicians and oncologists in the follow up of patients diagnosed with melanomas.

\section{CLINICAL CASE}

J.A.C., male, 56 years old. Diagnosed with melanoma in the right supraclavicular region, two years ago. Four months ago he went to the otorhinolaryngology

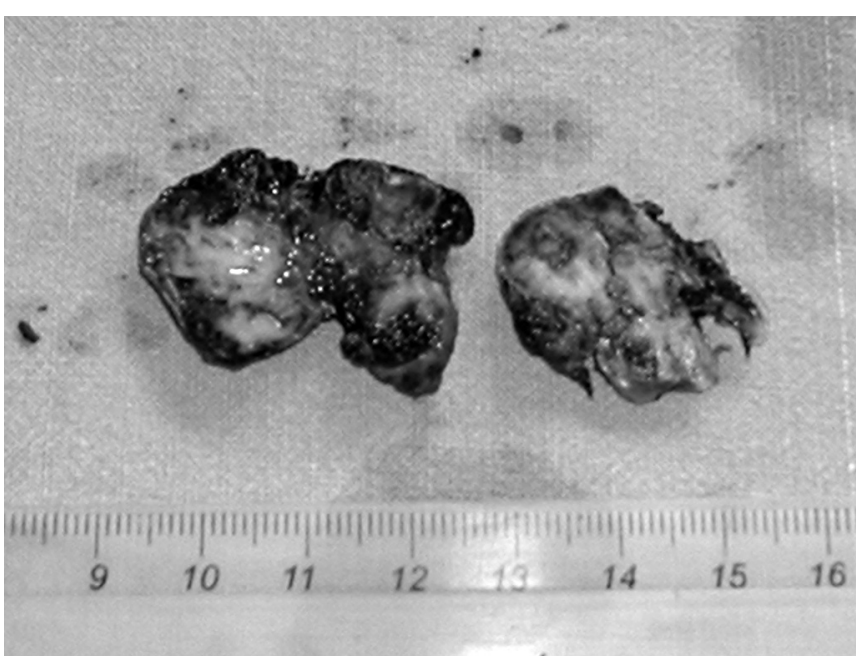

Figure 1. Macroscopy of palatine tonsils - right and left tonsils with hyperchromic areas. service complaining of persistent pharyngitis which did not go away with analgesics. He reported mild dysphagia and no fever. When physically examined, he showed good general condition, good color and eutrophic; anterior rhinoscopy and otoscopy without alterations. Oroscopy: Level II symmetric tonsils, presence of blackened hyperchromic lesion all over the right palatine tonsil. The lesion was irregular, painless and without inflammation signs. Left palatine tonsil and oral mucosa without alterations. Absence of cervical lymphnode hypertrophies. Pulmonary x-rays detected disseminated lesions on the parenchyma of both lungs. He was submitted to excisional biopsy of palatine tonsils at the Fortaleza General Hospital in May 2004. Surgical finding: right tonsil: blackened hyperchromic tissue with infiltrative aspect on the soft palate and abundant bleeding to resection; left tonsil: apparently without alterations, resection without difficulties. The histopathologist confirmed the presence of bilateral malignant melanoma metastasis on the tonsils, even with bilateral microscopic complication to histological cross sections (Figure 1). Chemotherapy was prescribed for the patient.

\section{DISCUSSION}

Melanoma is a tumor caused by the proliferation of atypical melanocytes located in the basal layer of the epithelium. From the clinical point of view, it is characterized by asymmetric, pigmented lesions with color variability (black, brown, pink, white), and irregular edges. It is invasive, with the possibility of metastasis to the lymphnodes, lungs, liver and brain6.

It is rare in the oropharynx. It has been described 3 that metastasis to palatine tonsils are normally late (about six and a half years), but this did not happen in the case described by us, which showed metastasis two years after detection of the initial lesion.

The clinical suspicion in the case presented was given by the previous history of cutaneous melanoma, confirmed by the histopathologist and by the clinical presentation of irregular pigmented lesion in the patient's tonsil. Despite the patient's complaint of only pharyngeal pain and irritation, the physical exam was essential to differentiate the pathology from a persistent viral or bacterial pharyngitis.

\section{REFERENCES}

1. Matthew H, Mraz-Gerhard S Primary cutaneous malignant melanoma and its precursor lesions: Diagnostic and therapeutic overview. J Am Acad Dermatol 2001; $45: 260-76$

2. Wakasugi S, Kageshita T, Ono T. Metastatic melanoma to the palatine tonsil with a favourable prognosis. Br J Dermatol 2001 Aug;145(2):327-9.

3. Cauchois R, Laccourreye O, Carnot F. Metastatic tonsil melanoma. Ann Otol Rhinol Laryngol 1993 Sep;102(9):731-4.

4. Murphy D, Gillen P. Metastatic melanoma of the tonsil. Ir Med J 2001 Sep;94(8):236-7.

5. Ramamurthy L, Nassar WY, Hasleton PS. Metastatic melanoma of the tonsil and the nasopharynx. J Laryngol Otol 1995 Mar;109(3):236-7.

6. Tueche SG. Behavior of malignant melanoma with tonsil metastasis. Ann Med Interne 2002 Mar;153(2):136-8.

Resident of Otorhinolaryngology at SESA/SUS - Fortaleza General Hospital SESA/SUS- Fortaleza General Hospital 